\title{
ALTERACIONES HISTOPATOLÓGICAS DE LOS BULBOS OLFATORIOS DE CACHAMA BLANCA ANTE UNA PRESENTACIÓN COMERCIAL DE GLIFOSATO: (ROUNDUP ${ }^{\circledR}$ ACTIVO)
}

Fecha de recepción: 19 de noviembre de 2014 • Fecha de evaluación: 19 de abril de 2015 • Fecha de aceptación: 23 de julio de 2015

\section{HISTOPATHOLOGICAL ALTERATIONS OF OLFACTORY BULBS OF WHITE CACHAMA TO A COMMERCIAL PRESENTATION GLYPHOSATE (Roundup ${ }^{\circledR}$ Activo)}

Diana C. Castañeda Cortés ${ }^{1}$ Edwin Gómez Ramírez • Hernán Hurtado Giraldo1,2

\section{RESUMEN}

El glifosato, en su presentación comercial Roundup ${ }^{\circledR}$ Activo, es un herbicida de amplio uso en Colombia. Se ha reportado que en Piaractus brachypomus este herbicida puede generar alteraciones a nivel cerebral incluyendo los bulbos olfatorios y se plantea que una de sus posibles vías de entrada al sistema nervioso central es el sistema olfativo. Por tal motivo, se pretende determinar las alteraciones histopatológicas del Roundup ${ }^{\circledR}$ Activo en los bulbos olfatorios de P. brachypomus. Se utilizaron 45 alevinos de P. brachypomus tratados con tres dosis $(0,0.1$ y $1 \mathrm{mg} / \mathrm{l})$ de Roundup ${ }^{\circledR}$ Activo durante un mes. Trascurrido un mes los cerebros fueron disectados, fijados y procesados para procesamiento en microscopia óptica de alta resolución. El tratamiento de $0 \mathrm{mg} / \mathrm{l}$ de Roundup ${ }^{\circledR}$ Activo no presentó alteraciones histopatológicas en las diferentes células de los núcleos neuronales se observaron normales. No obstante, los individuos expuestos a 0.1 y $1 \mathrm{mg} / \mathrm{d}$ de Roundup ${ }^{\circledR}$ Activo presentaron células granulares que se identificaron principalmente asociadas a los vasos sanguíneos de la pía madre del bulbo olfativo. La presencia de células granulares en los bulbos olfatorios es un indicativo de daños a nivel tisular. Teniendo en cuenta que el sistema olfativo está directamente implicado procesos vitales para los peces como la alimentación, la reproducción y el reconocimiento intra e inter específico; exposiciones prolongadas a este herbicida podrían afectar el adecuado desarrollo de P. brachypomus y su interacción con el ambiente.

Palabras clave: Células granulares, Roundup ${ }^{\circledR}$ Activo, sistema olfativo, Toxicología acuática, herbicidas.

1 Laboratorio de Embriología, Universidad Militar Nueva Granada, Grupo de Ictiología.

2 hernan.hurtado@unimilitar.edu.co 


\section{ABSTRACT}

Glyphosate, is an herbicide widely used in Colombia as Roundup ${ }^{\circledR}$ Activo. It has been reported that herbicide could cause alterations in the brain of Piaractus brachypomus including the olfactory bulbs and is propose as one of the possible routes of entry to the central nervous system is the olfactory system. Therefore, the aim is determine the histopathological alterations of Roundup ${ }^{\circledR}$ Activo in the olfactory bulbs of $P$. brachypomus. 45 P. brachypomus fry were used and treated with three doses (0, 0.1 and $1 \mathrm{mg} / \mathrm{I})$ Roundup ${ }^{\circledR}$ Activo for a month. One month after, the brains were dissected, fixed and processed for processing high resolution optical microscopy (HROM). The treatment of $0 \mathrm{mg} / \mathrm{l}$ of Roundup ${ }^{\circledR}$ Activo not present histopathological alterations in the different cells of neuronal nuclei. Nevertheless, individuals exposed to 0.1 and $1 \mathrm{mg} / \mathrm{l}$ of Roundup ${ }^{\circledR}$ Activo were identified granular cells mainly associated with blood vessels in the pia matter of the olfactory bulb. The presence of granule cells in the olfactory bulbs is indicative of damage in the tissue. The olfactory system is directly involved in vital processes in fish such as feeding, reproduction and intra- and inter-specific recognition; prolonged exposure to herbicide could affect the appropriate development of $P$. brachypomus and their interaction with the environment.

Keywords: Granular cell, Roundup ${ }^{\circledR}$ Activo, olfactory System, Aquatic Toxicology, herbicides.

\section{INTRODUCCIÓN}

Los herbicidas son ampliamente usados en ecosistemas terrestres y acuáticos para controlar las arvenses. Su uso ha generado serias preocupaciones sobre los efectos potencialmente adversos de estos químicos en el ambiente y en la salud humana (Lushchak et al. 2009). Durante las últimas décadas, el desarrollo de las actividades humanas ha repercutido en la disminución de la calidad de los ambientes acuáticos, particularmente por la contaminación extensiva con pesticidas y otros contaminantes, los cuales pueden ser transportados a los ambientes acuáticos por diferentes vías (Evrard et al. 2010).

El Roundup ${ }^{\circledR}$ es una presentación comercial del glifosato. Este es un herbicida de con mayor espectro y el más usado en el mundo (Kolpin et al. 2006). Sin embargo, el uso del glifosato no solo afecta los ecosistemas terrestres, también puede llegar a los ecosistemas acuáticos, ya sea por lixiviación, escorrentía, aspersión accidental y/o por el viento (Kolpin et al. 2006). En Colombia la formulación comercial Roundup ${ }^{\circledR}$ Activo se utiliza como herbicida en la agricultura tradicional, como desecante de granos, madurante de la caña de azúcar y además para la erradicación forzosa de cultivos ilícitos por medio de aspersiones aéreas (Nivia 2001, Rodón-Barragan et al. 2007). Sin embargo, para la erradicación de estos cultivos, se utilizan dosis muy altas de Roundup ${ }^{\circledR}$ Ultra, los fabricantes de este producto recomiendan que las concentraciones para la mezcla de aspersión estén entre 1,6 y $7,7 \%$ y que la tasa aspersión sea de 2,33 I/ha, pero en Colombia se utilizan concentraciones de hasta $44 \%$ y una tasa de aspersión de 30,8 I/ ha (Eslava et al. 2007).

Se han estudiado los efectos del glifosato y su formulación en diferentes organismos acuáticos, los cuales producen diferentes grados de toxicidad 
(Achiorno et al. 2008). Los surfactantes no iónicos, como el POEA, causan problemas en las superficies respiratorias de los organismos acuáticos (Dinehart et al. 2009). Un estudio realizado por Lushchak et al. 2009, mostró que concentraciones bajas de herbicida puede causar efectos muy marcados en peces. Se reporta que la toxicidad aguda del Roundup ${ }^{\circledR}$ para peces se encuentra en un rango de 2 - 55 $\mathrm{mg} / \mathrm{l}$, pero varía según la especie, el estadio de desarrollo, la temperatura del agua, el pH y la dureza (Ramírez et al. 2004).

Un estudio realizado por Glusczak et al. 2006 en Leporinus obtusidens y por Glusczak et al. 2007 en Rhamdia quelen, especies de agua dulce, que habitan al sur de Brasil, mostró que la actividad de la acetílcolinesterasa en el cerebro disminuye a causa de la exposición a POEA. Debido a la disminución en los niveles de la enzima, se acumula acetilcolina causando alteraciones en el nado y letargia, este estudio confirma que el POEA es el componente más tóxico del herbicida Roundup ${ }^{\circledR}$.

La reducción de la acetílcolinesterasa encontrada en Prochilodus lineatus en el cerebro y el músculo después de $96 \mathrm{~h}$ de exposición también fueron encontrados en $L$. obtusidens y $R$. quelen expuestos al mismo herbicida (Gusczak et al. 2006, Modesto \& Martínez, 2010). Modesto \& Martínez 2010 hicieron el primer reporte de inhibición de acetílcolina en el musculo de peces expuestos a glifosato, la acumulación de acetílcolina debido a la reducción de la actividad de la enzima puede afectar el comportamiento reproductivo de los peces (Bretaud et al. 2000).

Se ha reportado que el Roundup ${ }^{\circledR}$ causa problemas en las superficies respiratorias de los organismos acuáticos (Dinehart et al. 2010), y en Cachama Blanca (Piaractus brachypomus) existen estudios que demuestran las alteraciones morfológicas causadas por esta formulación de glifosato en órganos como hígado, riñón, estómago, intestino, branquias, piel y cerebro (Eslava et al. 2007). Son pocos los estudios que se han realizado sobre el efecto de este herbicida a nivel del sistema nervioso central, en particular en el sistema olfativo. Los trabajos adelantados por el grupo de Sanidad de la Universidad de los Llanos reportan alteraciones en el telencéfalo y los bulbos olfativos de esta especie, planteando que una de las posibles vías de entrada de este herbicida al sistema nervioso central es el sistema olfativo. A pesar de ser uno de los sistemas sensoriales más importantes en la interacción de los peces con su ambiente por estar relacionado directamente con la obtención de alimento, la defensa de predadores y la reproducción (Hamdani \& Døving 2007).

Teniendo en cuenta las razones anteriormente expuestas y que $P$. brachypomus es una especie endémica de las regiones de la Orinoquía y Amazonía (Agudelo et al. 2011) y una de los mas importantes en Colombia en las últimas décadas, ocupando el tercer lugar de los peces de consumo cultivados $(\mathrm{CCl}$ 2011, Pineda et al., 2004), la cual ha sido sometida a continuas fumigaciones con herbicida, esta especie sería un buen modelo estudio para determinar los efectos causados por el Roundup ${ }^{\circledR}$ Activo. La universidad Militar Nueva Granada ha adelantado estudios enfocados a la descripción histológica del sistema digestivo, hipófisis, ganglios de la raíz dorsal y cerebro de esta especie (Caldas et al., 2008, Jaramillo et al., 2009, Muñoz et al., 2006).

Este artículo tiene como objetivo describir de manera detallada las posibles alteraciones tisulares generadas por dos concentraciones subletales de Roundup ${ }^{\circledR}$ Activo $(0.1$ y $1 \mathrm{mg} / \mathrm{l})$ sobre las diferentes estructuras del sistema olfativo de P. brachypomus.

\section{MATERIALES Y MÉTODOS}

El estudio se realizó en los Laboratorios de Embriología y Fisiología Animal del programa de Biología Aplicada, de la Facultad de Ciencias Básicas de la Universidad Militar Nueva Granada, sede Campus Cajicá (Cundinamarca). 
Se trabajó con alevinos de Cachama blanca ( $P$. brachypomus) de 30 días después de la eclosión de un mismo desove, los cuales fueron adquiridos en la estación piscícola del Instituto de Acuicultura de los Llanos. Los peces fueron mantenidos en acuarios de vidrio de $40 \mathrm{~L}$ de agua, con aireación constante y sin filtro, se alimentaron tres veces al día (9:00, 12:00 y 16:00 horas) con "Mojarrina" al 35\% de proteína bruta ajustada al $5 \%$ de la biomasa total. La temperatura promedio del agua se mantuvo entre $24-29^{\circ} \mathrm{C}$, con un fotoperíodo de 12:12 h (luz/oscuridad). Los parámetros de calidad de agua (oxígeno disuelto: mayor de $3 \mathrm{mg} / \mathrm{l}, \mathrm{pH}$ : 6.5 a 8.5, amonio: $0.1 \mathrm{mg} / \mathrm{l}$ ) fueron medidos semanalmente.

Se utilizó la marca comercial Roundup ${ }^{\circledR}$ Activo del herbicida glifosato, compuesto por un $48 \%$ de sal ácida isopropilamina de glifosato (IPA) y surfactante que para esta formulación la casa Monsanto no aclara cual es y en qué porcentaje lo contiene (Tsui y Chu, 2003; Oldham et al., 2002).

Con el fin de evitar los efectos deletéreos del glifosato sobre el ambiente, el agua que se utilizó en el experimento se mantuvo en tanques plásticos por un periodo de 30 días para permitir la evaporación y transformación del herbicida y pasado este tiempo fue percolada en el suelo (Soso et al., 2007).

El diseño experimental fue completamente aleatorizado con tres replicas por tratamiento. El estudio evaluó dos concentraciones subletales de herbicida Roundup ${ }^{\circledR}$ Activo, de la siguiente manera: el tratamiento 1 sin Roundup $^{\circledR}$, el tratamiento 2 con una concentración $0.1 \mathrm{mg} / \mathrm{l}$ de Roundup ${ }^{\circledR}$ Activo y el tratamiento 3 contenía una concentración de $1 \mathrm{mg} / \mathrm{l}$ de Roundup ${ }^{\circledR}$ Activo. En cada unidad experimental (acuario 40 L) se manejó una densidad de 20 peces/ acuario. Se realizaron recambios diarios del $50 \%$ del volumen de agua, manteniendo la concentración a través de la adición de la mitad de la dosis (RondonBarragan et al., 2007). Los peces fueron mantenidos durante 30 días bajo estas condiciones, transcurrido este tiempo se registraron variables de crecimiento (peso, la longitud total y estándar).

Se muestrearon 16 individuos por tratamiento aleatoriamente para procesamiento histológico, fueron anestesiados con Benzocaina ( $0.1 \mathrm{~g} / \mathrm{L})$ y posteriormente sacrificados por un corte medular a nivel cervical. Este trabajo siguió los lineamientos indicados para el manejo peces ético de los en la investigación (CCAC guidelines on: the care and use of fish in research, teaching and testing, 2005).

Se utilizaron para el procesamiento de Microscopia Óptica de Alta Resolución. 3 individuos de cada tratamiento y se procesaron modificando las metodologías publicadas por Caldas et al. (1993) como se describe a continuación:

Fijación: Después de sacrificar al individuo, se realizó la disección de los bulbos olfativos que fueron fijados en Karnovsky modificado: una solución de Formaldehido al 2\% y Glutaraldehido al 2.5\% en buffer fosfato, durante dos horas. Posteriormente se hicieron tres lavados con buffer fosfato, cada uno de 10 minutos.

Postfijación: en este caso se utilizó Tetraóxido de Osmio al $2 \%$ con buffer fosfato durante tres horas. Después de la postfijación se hicieron tres lavados con buffer fosfato cada uno de 10 minutos.

Deshidratación: se introdujo el tejido en concentraciones ascendentes de $70 \%, 90 \%, 95 \%$ y $100 \%$ preparados a partir de etanol absoluto.

Inclusión en resina epóxica: las muestras deshidratadas se impregnaron en resina Poli/Bed ${ }^{\circledR 8} 812$ mezclada con óxido de propileno.

Cortes y tinción: se realizaron cortes trasversales con la ayuda de un micrótomo rotatorio (Microm Slee Cut 4060), a 1 micra de espesor. Se tiñeron con azul de toluidina durante 30 ○ 40 segundos al calor (Caldas et al 1993).

Se realizaron observaciones con el microscopio de luz (marca CARL ZEISS AXIOSKOP PLUS), y se procedió a la captura de imágenes con la cámara CANON 
Power Shot G5 para la identificación de alteraciones histopatológicas: se identificaron células granulares y granulares eosinofílicas, en el la roseta olfativa y el bulbo olfativo, siguiendo las descripciones realizadas por Ramírez et al. 2008 y Reite \& Evense 2006.

\section{RESULTADOS}

En los cortes teñidos con H\&E del bulbo olfativo, no se observaron CGE en ninguno de los tratamientos. Por el contrario en las secciones obtenidas con MOAR para el T2 y el T3 se evidenciaron células granulares CG, que fueron caracterizadas por la gran afinidad que tienen los gránulos de estas células al azul de toluidina. La mayoría de las CG observadas están cercanas a los vasos sanguíneos que se encuentran en las meninges que cubren el bulbo olfativo (Figuras 1. A, C , D y 2. A, B, D). También se observaron unas pocas $C G$ en la capa del nervio olfativo y en la capa glomerular cercanas a células mitrales o vasos sanguíneos (Figuras 1 B,E y 2 C,E).

\section{DISCUSIÓN}

El principal cambio histológico observado en los individuos expuestos a Roundup ${ }^{\circledR}$ Activo con respecto a los individuos control, es la presencia de células granulares (CG), que en el caso del epitelio olfativo se denominaron células granulares eosinofílicas (CGE), debido a la tinción con H\&E (Reite, 1997).

Las CG/CGE en peces están asociadas con los mecanismos de respuesta a procesos infecciosos de
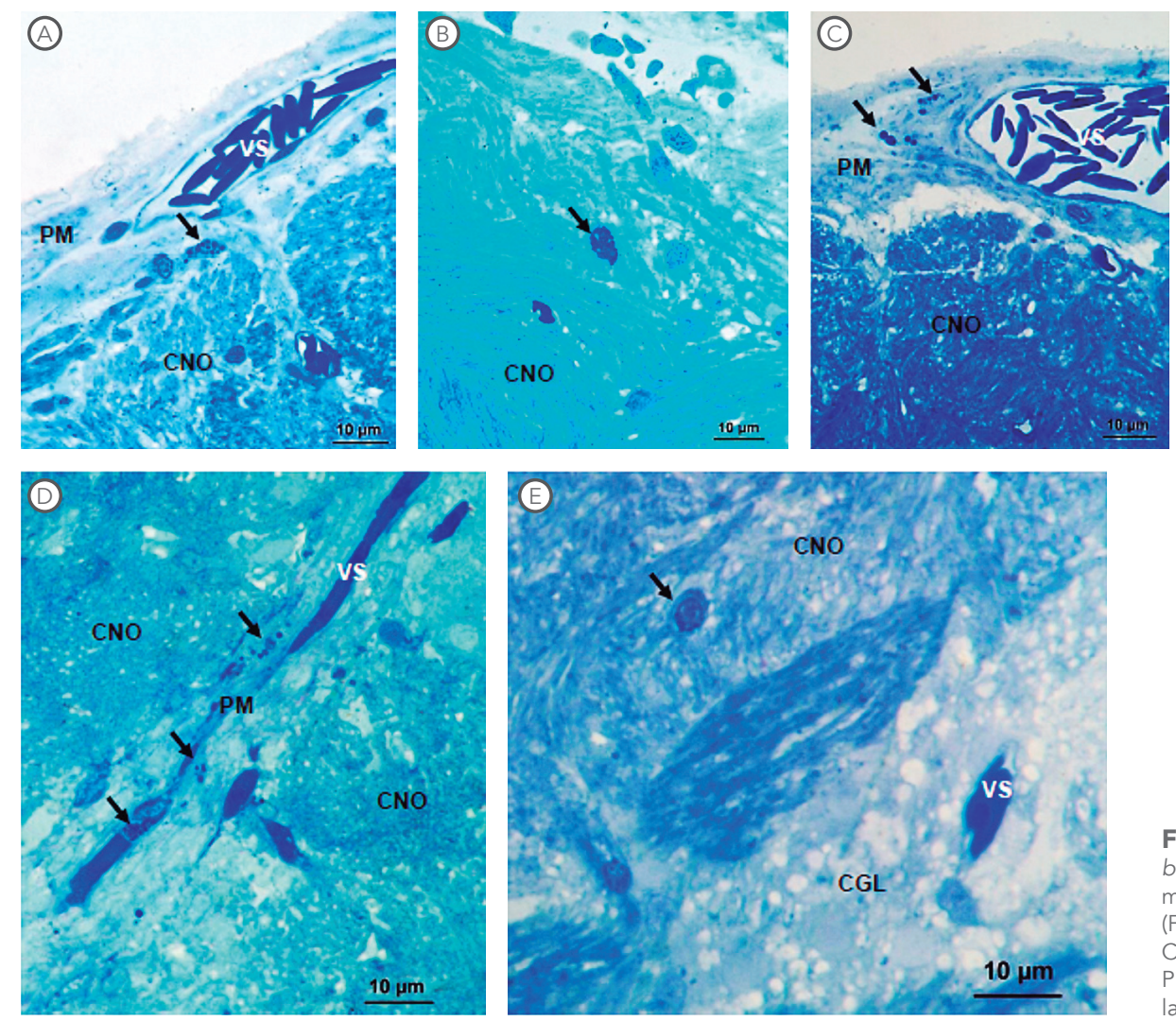

Figura 1. Bulbo olfativo de $P$. brachypomus. Cortes del tratamiento 2 A-E) Células granulares (Flechas), vaso sanguíneo (VS). Capa del nervio olfativo (CNO), Pia madre (PM) y capa glomerular (CGL). Azul de toluidina. 

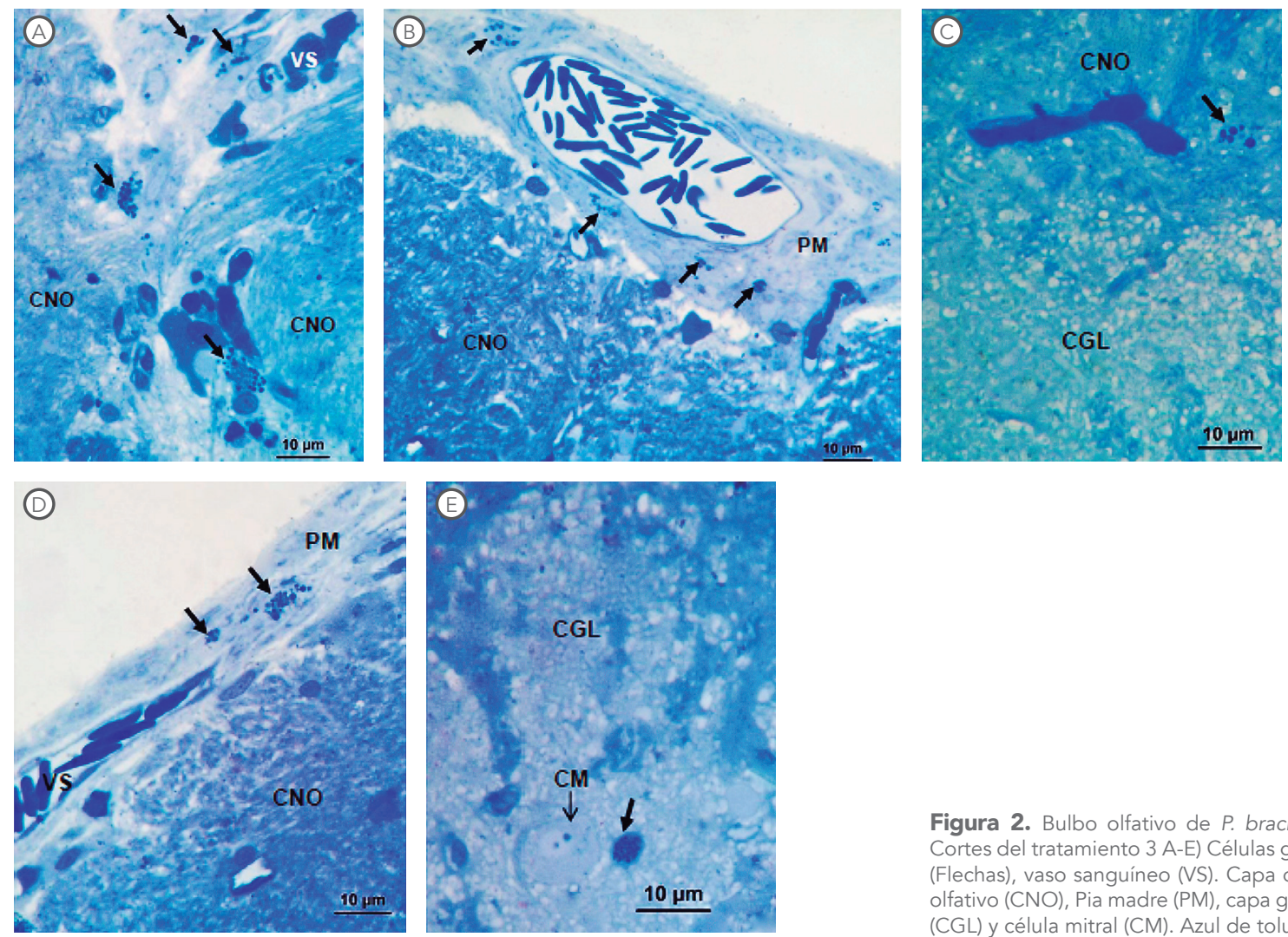

Figura 2. Bulbo olfativo de P. brachypomus. Cortes del tratamiento $3 \mathrm{~A}-\mathrm{E}$ ) Células granulares (Flechas), vaso sanguíneo (VS). Capa del nervio olfativo (CNO), Pia madre (PM), capa glomerular (CGL) y célula mitral (CM). Azul de toluidina.

los tejidos ya sea por parásitos o agentes citotóxicos (Cammarata et al., 2000, Dezfuli et al., 2003). Algunos autores sugieren que las CG/CGE son homólogas de las células mast de los mamíferos (Dezfuli et al. 2010 y Retie \& Evensen 2006) las observaciones realizadas en el presente estudio apoyan esta hipótesis, debido a que la morfología de las CG/CGE observadas (en especial el citoplasma lleno de gránulos), junto con su distribución en los tejidos y sus propiedades de tinción coinciden con estos reportes.

Numerosos estudios reportan el aumento de las CGE en los tejidos después de la exposición a agentes inmunotóxicos (Dezfuli \& Giari 2008, Schmale et al. 2004). En este trabajo aunque no se realizaron conteos del número de CGE presentes en el epitelio olfativo de los diferentes tratamientos, de manera cualitativa se observó un aumento considerable en el número de CGE en el tratamiento 3 (1 mg/l) con respecto al T2 $(0.1 \mathrm{mg} / \mathrm{l})$, lo cual sugiere que la concentración de $1 \mathrm{mg} / \mathrm{l}$ de Roundup ${ }^{\circledR}$ Activo puede generar un grado mayor de daño en el epitelio olfativo.

Por lo general las CGE están asociadas principalmente a los vasos sanguíneos del tejido conectivo (Lauriano et al. 2012, Matsuyama \& lida 1999, Retie \& Evensen 2006), se cree que los precursores de estas células se originan en sistema hematopoyético y viajan a través del torrente sanguíneo hacia los tejidos, migrando y terminando de diferenciándose para llevar a cabo sus funciones (Galli 1990, Kirshenbaum et al. 1991). Sin embargo, en el presente 
estudio las CGE fueron comúnmente encontradas en la región basal del epitelio olfativo no sensorial y no en el núcleo central, donde se encuentran numerosos vasos sanguíneos.

Por lo anterior en este trabajo se plantea la hipótesis que los precursores de estas células residen en este epitelio y solo se diferencian cuando se produce una señal de alarma, generando una respuesta rápida a cualquier agente nocivo. Esta hipótesis es apoyada por estudios realizados en branquias, donde Flaño et al. 1996 infectaron cultivos de tejidos branquiales de O. mykiss con Renibacterium salmoninarum, causando un aumento en el número de CGE. Y en otro estudio con Sparus aurata, se encontró que después de la exposición a bifenilo piliclorado PCB 126 (compuesto organoclorado), las branquias presentaban un aumento de CGE que no estaban asociadas a los vasos sanguíneos (Lauriano et al. 2012). Las branquias al igual que la roseta olfativa son órganos inmunológicos importantes, que están en contacto directo con el ambiente por lo cual siempre deben estar alerta a cualquier cambio en el ambiente que pueda generar una reacción inmunológica (Tierney et al. 2010).

Por otra parte en el bulbo olfativo, también se observó la presencia de células granulares (CG) en los individuos expuestos a Roundup ${ }^{\circledR}$ Activo, en este caso fueron identificadas en cortes teñidos con azul de toluidina, el cual tiñe fuertemente los gránulos de estas células. Al igual que lo reportado en otros peces, estas células presentan poblaciones heterogéneas con diferentes morfologías y contenido granular (Dezfuli et al. 2010, Retie \& Evensen 2006).

La mayoría de CG observadas en el bulbo olfativo, están asociadas a los vasos sanguíneos de la pía madre, característica común descrita en otros vertebrados (Retie \& Evensen 2006). Esta asociación con las células capilares siguiere que las CG migran a través del endotelio, hasta llegar al lugar donde deben cumplir sus funciones (Powell et al.
1990). Teniendo en cuenta que las CG fueron observadas en la capa del nervio olfativo y en la capa glomerular del bulbo, y en algunos casos cercanas a las células mitrales, se puede decir que las CG si presentaron migración a diferentes partes del bulbo olfativo. Algunos autores describen que una vez las CG han madurado y migrado ocurre la degranulación, se cree que este evento es inducido por el compuesto 48/80 (polímero) (Retie 1997), liberando o produciendo sustancias que intervienen en la reacción inflamatoria de los tejidos como histamina y de péptidos antimicrobianos (Noga \& Silphaduang 2003, Silphaduang \& Noga 2001).

Por otro lado, según los reportado por Wilhelm et al. 2005, en mamíferos las células mast (homologas de las CG) pueden interactuar con las neuronas por procesos de transgranulación, ya sea por fusión directa de los gránulos y las membranas plasmáticas de ambas células, por la captura de restos de gránulos insolubles tras los eventos de degranulación de las células mast o por endocitosis de estas.

Son pocos los estudios acerca del papel de las CG en el cerebro de peces, de hecho los primeros reportes de la aparición de CG en el cerebro tras la exposición a surfactantes (Cosmoflux ${ }^{\circledR}$ ) o herbicidas (Roundup ${ }^{\circledR}$ ), fueron realizados por Rondón-Barragan et al. 2007 y Ramírez et al. 2008 respectivamente. En este último estudio se encontraron CGE en el telencéfalo y en el bulbo olfativo de $P$. brachypomus, utilizando concentraciones mayores de Roundup ${ }^{\circledR}$ (desde 7,5 a $120 \mathrm{mg} / \mathrm{l}$ ) a las utilizadas en el presente trabajo. Ramírez et al. 2008 reportaron daños como gliosis y presencia de CGE alrededor de neuronas con procesos degenerativos, tal vez desencadenando o acelerando eventos de muerte celular.

Aunque estos daños neurodegenerativos no fueron observados en el presente trabajo, posiblemente debido a que las concentraciones de Roundup ${ }^{\circledR}$ evaluadas fueron menores a las utilizadas por Ramírez et al. 2008. Aun así es muy importante destacar 
que este es uno de los primeros reportes de CG/ CGE en el sistema olfativo tras la exposición a concentraciones subletales de este herbicida (0.1 y 1 $\mathrm{mg} / \mathrm{l})$, que se encontraron disueltas en los ecosistemas acuáticos (Eslava et al. 2007), por ende es más pertinente evaluar el efectos de estas concentraciones. De esta manera la presencia de CGE indica que hay una reacción y un cambio histopatológico en el sistema olfativo de P. brachypomus, por tanto se hace importante realizar estudios más profundos que determinen las funciones que las CG cumplen en estos tejidos, como se relacionan con las neuronas, que tipo de compuestos secretan y como estos influyen en las neuronas.

\section{AGRADECIMIENTOS}

A la Universidad Militar Nueva Granada y a la Vicerrectoría de Investigaciones por la financiación de este proyecto CIAS 1061.

\section{REFERENCIAS}

1. Achiorno CL, Villalobos C, Ferrari L. 2008.Toxicity of the herbicide glyphosate to Chordodes nobilii (Gordiida, Nematomorpha). Chemosphere, 71: 1816-1822.

2. Agudelo C, Pineda Z, Acosta S, Ramírez G, Ajiaco M, Gonzales C. 2011. Piaractus brachypomum (Cuvier 1818). p. 236-242. En: Lasso A, Agudelo C, Jimenez S, Ramirez G, Morales B, Ajiaco M, Gutierrez F, Usma O, Muñoz, Sanabria O. 2011. Catalogo de recursos pesqueros continentales en Colombia. Serie editorial recursos hidrobiológicos y pesqueros continentales de Colombia. Instituto de investigaciones de los recursos biológicos Alexander von Humboldt. Bogotá, Colombia.

3. Bretaud S, Toutant JP, Saglio P. 2000. Effects of carbofuran, diuron and nicosulfuron on acetylcholinesterase activity in goldfish (Carassius auratus). Ecotoxicol. Environental, 47: 117-124.

4. Caldas ML, Hurtado H, Barrera B. 2008. Estudio histológico y morfológico preliminar de la hipófisis de alevinos de cachama blanca Piaractus brachypomus, (Characidae: Piaractus). Actualidades Biológicas, 30 (89): 100-110

5. Caldas ML, Ricaurte $O$, Rodríguez G, Amaya J. 1993. Microscopía óptica de alta resolución "MOAR". Instituto Nacional de Salud. Bogotá, Colombia.

6. Cammarata M, Vazzana M, Cervello M, Arizza V, Parrinello N. 2000. Spontaneous cytotoxic activity of eosinophilic granule cells separated from the normal peritoneal cavity of Dicentrarchus labrax. Fish Shellfish Immunol, 10:143-54

7. CCAC. Canadian Council on Animal Care. 2005. Guidelines on: the care and use offish in research, teaching and testing. Ottawa, Ontario, Canada: Canadian Council on Animal Care.

8. Dezfuli BS, Giari L, Simoni E, Palazzi D, Manera M. 2003. Alteration of rodlet cells in chub 
caused by herbicide Stam ${ }^{\circledR}$ M-4 (Propanil). J Fish Biol;63:232-9.

9. Dezfuli BS, Giovinazzo G, Lui A, Giari L. 2008. Inflammatory response to Dentitruncus truttae (Acanthocephala) in the intestine of brown trout. Fish Shellfish Immunol, 24:726-33.

10. Dezfuli BS, Pironi F, Giari L, Noga EJ. 2010. Immunocytochemical localization of piscidin in mast cells of infected seabass gill. Fish \& Shellfish Immunology 28: 476-482

11. Dinehart SK, Smith LM, McMurry ST, Smith PN, Anderson TA, Haukos DA. 2010. Acute and chronic toxicity of Roundup Weathermax and Ignite $280 \mathrm{SL}$ to larval Spea multiplicata and S. bombifrons from the Southern High Plains, USA. Environ Pollut,158(8): 2610-7.

12. Eslava-Mocha PR, Ramirez-Duarte WF, RondonBarragan IS. 2007. Sobre los efectos del glifosato y sus mezclas: Impacto sobre peces nativos. Universidad de los Llanos. Colombia, 150 p.

13. Evrard E, Marchand J, Theron M, PichanvantRafini K, Durand G, Quiniou L, Laroche J. 2010. Impacts of mistures of herbicides on molecular an physiological responses of the European flounder Platichthys flesu. International journal Comparative Biochemistry and Physiology, 152(3): 321-31.

14. Flaño E, Lopez-Fierro P, Rasquin BE, Villena A. 1996. In vitro differentiation of eosinophilic granular cells in Renibacterium salmoninaruminfected gill cultures from rainbow trout. Fish \& Shellfish Immunology 6:173-84.

15. Galli SJ. Biology of disease. 1990. New insights into "The riddle of the mast cells": microenvironmental regulation of mast cell development and phenotypic heterogeneity;62:5-33.

16. Glusczak L, Santos DM, Crestani M, Fonseca MB, Araujo FP, Frescura MD, Pimentel V L. 2006. Effect of glyphosate herbicide on acetylcholinesterase activity and metabolic and hematological parameters in piava (Leporinus obtusidens). Ecotoxicology and Environmental Safety, 65: 237-241.

17. Glusczak L, Santos DM, Silveira MB, Rodrigues RS, Chitolina MRS, Morsch VM Loro VL. 2007. Acute effects of glyphosate herbicide on metabolic and enzymatic parameters of silver catfish (Rhamdia quelen) Comparative Biochemistry and Physiology, Part C 146: 519-524.

18. Hamdani EH, Døving KB. 2007. The functional organization of the fish olfactory system. Progress in Neurobiology, 82: 80-86.

19. Jaramillo J, Gómez E, Caldas ML, Rodríguez D, Hurtado H. 2009. Histology and morphometry of dorsal root ganglia and their neurons in a fish of indeterminate growth the white cachama (Piaractus brachypomus). Actualidades Biológicas, 31: 43-52.

20. Keith B. Tierney, David H. Baldwin, Toshiaki J. Hara, Peter S. Ross, Nathaniel L. Scholz, Christopher J. Kennedy. 2010. Olfactory toxicity in fishes. Aquatic Toxicology, 96: 2-26.

21. Kirshenbaum AS, Kessler SW, Goff JP, Metcalfe DD. 1991. Demonstration of the origin of human mast cells from CD34Cbone marrow progenitor cells. Journal of Immunology; 146:1410-5.

22. Kolpin D, Thurman M, Lee E, Meyer M, Furlong E, Glassmeyer S. 2006. Urban contributions of gliphosate and its degradate AMPA to streams in the United States. Journal Science of the total environment, 354: 191-197.

23. Lushchak O, Kubrak O, Storey J, Storey K, Lushchak VI. 2009. Low toxic herbicide Roundup induces mild oxidative stress in goldfish tissues. International Journal Chemosphere, 76: 932-937.

24. Modesto KA, Martinez CBR. 2010. Roundup ${ }^{\circledR}$ causes oxidative stress in liver and inhibits acetylcholinesterase in muscle and brain of 
the fish Prochilodus lineatus. Chemosphere, 78:294-299.

25. Muñoz A, Caldas ML, Hurtado H. 2006. Análisis histomorfométrico del sistema digestivo y glándulas anexas de alevino de cachama blanca. Revista Facultad De Ciencias Básicas, 2 (1): 33-45.

26. Nivia E. 2001. Conferencia: Las Guerras en Colombia: Drogas, Armas y Petróleo" "The Wars in Colombia: Drugs, Guns and Oil" Instituto Hemisférico de las Américas Universidad de California, Davis, Mayo 17-19, 2001 Las fumigaciones aéreas sobre cultivos ilícitos si son peligrosas - Algunas aproximaciones.

27. Noga EJ, Silphaduang U. 2003. Piscidins: a novel family of peptide antibiotics from fish. Drug News Perspect 16:87-92.

28. Oldham J, Massey R, Cryan P. 2002. Aerial spraying in Colombia: and environmental effects. The Institute for Science \& Interdisciplinary Studies (Fact Sheet) 4p.

29. Pineda SH, Olivera AM, Urcuqui IS, Builes GJ, Trujillo BE. 2004. Polimorfismo genético en cachama blanca Piaractus brachypomus (Characidae, Serrasalminae) mantenida en cautiverio. Il Congreso Colombiano de Acuicultura. Villavicencio. p. 49-50.

30. Powell MD, Wright GM, Burka JF. 1990. Eosinophilic granule cells in the gills of rainbow trout, Oncorhynchus mykiss: evidence of migration? J Fish Biol;37:495-7.

31. Ramírez-Duarte WF, Rondón-Barragán IS, Eslava-Mocha PR. 2008. Acute toxicity and histopathological alterations of Roundup $®$ herbicide on "cachama blanca" (Piaractus brachypomus). Pesq. Vet. Bras, 28 (11): 547-554.

32. Ramirez-Duarte WF, Rondon-Barragan IS, Vidal Barrios HH, Eslava-Mocha PR. 2004. Efectos del glifosato (GP) con énfasis en organismos acuáticos. Orinoquia, 7 (1-2): 70-100.
33. Reite OB, Evensen O. 2006. Inflammatory cells of teleostean fish: A review focusing on mast cells/eosinophilic granule cells and rodlet cells. Fish \& Shellfish Immunology, 20(2): 192-208.

34. Reite OB. 1997. Mast cells/eosinophilic granule cells of salmonids: staining properties and responses to noxious agents. Fish \& Shellfish Immunology, 7:567-84.

35. Rondón-Barragán IS, Ramírez-Duarte WF, Eslava-Mocha PE. 2007. Evaluación de los efectos tóxicos y concentración letal 50 del surfactante Cosmoflux ${ }^{\circledR} 411 \mathrm{~F}$ sobre juveniles de cachama blanca (Piaractus brachypomus). Rev Col Cienc Pec, 20: 431 - 446.

36. Schmale MC, Vicha D, Cacal SM. 2004. Degranulation of eosinophilic granule cells in neurofibromas and gastrointestinal tract in the bicolor damselfish. Fish Shellfish Immunol, 17:53-63.

37. Silphaduang U, Noga E. 2001. Peptide antibiotics in mast cells of fish. Nature;414:268-9.

38. Soso AB, Gil Barcellos LJ, Ranzani-Paiva MJ, Kreutz LC, Quevedo RM, Anziliero D, Lim M, Bolognesi da Silva L, Ritter F, Calliari Bedin A, Finco JA. 2007. Chronic exposure to sublethal concentration of a glyphosate-based herbicide alters hormone profiles and affects reproduction of female Jundiá (Rhamdia quelen). Environmental Toxicology and Pharmacology, 23: 308-313.

39. Tsui TK, Chu LM. 2003. Aquatic toxicity of glyphosate-based formulations: comparison between different organisms and the effects of environmental factors. Chemosphere, 52: 1189-1197.

40. Wilhelm M, Silver R, Silverman AJ. Central nervous system neurons acquire mast cell products via transgranulation. Eur J Neurosci 2005; 22:2238-2248. 